\title{
Quercetin attenuates, indomethacin-induced acute gastric ulcer in rats
}

\author{
A.G.R. Alkushi ${ }^{1}$, N.A.M. Elsawy ${ }^{2}$ \\ ${ }^{1}$ Department of Anatomy, Faculty of Medicine, Umm Al-Qura University, Makkah, Saudi Arabia \\ 2Department of Anatomy and Embryology, Faculty of Medicine, Zagazig University, Egypt
}

[Received: 12 February 2016; Accepted: 23 August 2016]

Background: Peptic ulcer diseases are common and are induced by many factors, including stress, smoking, and ingestion of non-steroidal anti-inflammatory drugs. Quercetin is considered to be an anti-oxidant with healing effects on many experimental toxic injuries. The present study aimed to explore the possible effect of quercetin on acute gastric ulcer induced by indomethacin in rats.

Materials and methods: Three groups received indomethacin (30 mg/kg body weight) orally by orogastric gavage on two consecutive days. The rats received famotidine (50 mg/kg body weight), quercetin (50 mg/kg body weight), or vehicle alone for 15 consecutive days by oral gavage. The control group received no indomethacin but received vehicle for 15 days by oral gavage. The ulcer index, volume, and pH of gastric juice were measured, and the stomachs were examined by routine light microscopy.

Results: Compared with the control group, the indomethacin-treated rats showed a marked damage of the gastric mucosal surface and a high ulcer index. In the famotidine- and quercetin-treated groups, significantly increased antioxidant enzyme activities were observed. The congestion, erosions, and necrosis were reduced with mild inflammatory cell infiltration while no major damage of endothelial cells was observed in the treated rats.

Conclusions: The findings of the study show that quercetin had antioxidant effect and can protect gastric mucosa against indomethacin-induced gastric ulceration than famotidine. (Folia Morphol 2017; 76, 2: 252-261)

Key words: flavonoids, ulceration, nonsteroidal anti-inflammatory drugs, $\mathrm{pH}$ value, gastric juice

\section{INTRODUCTION}

An inflammation, irritation or erosion of the mucosal surface of the stomach is termed as gastritis, and it can range from a mild, asymptomatic form to severe ulceration [67]. When a gastric ulcer occurs in the lining of the stomach, it is known as a peptic ulcer, which refers to an open sore in the lining of the stomach or the duodenum [51]. Peptic ulcers are associated with high morbidity and morbidity and mortality related to many complications including bleeding, perforation, penetration and gastric outlet obstruction [6, 42, 51]. Moreover, many otherwise beneficial therapies, including low-dose aspirins, dual anti-platelet therapy and nonsteroidal anti-inflammatory drugs (NSAIDs) such as indomethacin, have been shown to be important risk factors for recurrent ulcers and related complications [61]. It has been reported that about $25 \%$ of gastric ulcers are caused by NSAIDs [11]. NSAIDs are widely used for pain control and prevention of malignancies, strokes, pre-eclampsia, 
Alzheimer's disease, etc. [60, 73]. Furthermore, studies have reported that various non-pharmaceutical factors including stress, hunger and Helicobacter pylori invasion also cause gastric ulcers [63]. Hence, the prevention of gastrointestinal disorders, including gastric ulcers, is of utmost importance for both medical professionals and researchers.

Many synthetic anti-ulcer drugs (e.g., misoprostol) have been developed that can be specifically used for preventing or treating NSAID-induced gastric ulcers [44]. However, these drugs have many side-effects such as diarrhoea, itching, skin rash, and dizziness [20]. Therefore, there is a renewed interest in nontoxic, natural anti-ulcer formulations from medicinal plants [52]. Flavonoids are a naturally-occurring group of compounds with anti-inflammatory, anti-allergic, anti-viral, anti-bacterial and anti-tumour activities [14, 72]. One of these flavonoids, quercetin $(3,5,7,3$, 4 '-pentahydroxyflavone), has been reported to have the ability to prevent oxidant injury and cell death by scavenging free oxygen radicals [43]. Quercetin is widely distributed in fruits and vegetables such as onions, apples, berries, and tea [48]. Studies have shown that daily intake of quercetin may decrease the risks of cardiovascular diseases [39], tumour development, strokes and neurodegenerative diseases [53] by protection against oxidative DNA damage [21], lipid peroxidation [38] and inhibition of the release of inflammatory mediators [41]. Presently, quercetin is marketed in the United States primarily as a dietary supplement [69], with a recommended daily dose of 200-1200 mg (probably due to variable absorption from the digestive tract) [19].

Experimental studies have shown that quercetin can prevent ethanol-induced gastric ulcers [31]. Therefore, the present study was undertaken to extend this finding by examining the effects of quercetin on indomethacin-induced gastric lesions in rats.

\section{MATERIALS AND METHODS}

\section{Animal grouping}

Forty adult male albino rats (150-250 g body weight) were obtained from the animal house, Faculty of Medicine, Umm Al-Qura University. All animal procedures were performed according to the approved protocols and in accordance with the recommendations for the proper care and use of laboratory animals. The animals were categorised into four groups (10 in each):
- Group 1 (control) received $1 \mathrm{~mL}$ of $1 \%$ sodium carboxymethyl cellulose (CMC) by oral gavage for 15 consecutive days;

- Group 2 received indomethacin $(30 \mathrm{mg} / \mathrm{kg}$ body weight) dissolved in 1\% CMC for 2 days, followed by $1 \%$ CMC for 15 consecutive days;

- Group 3 received indomethacin in 1\% CMC as in Group 2 and additionally received famotidine (50 mg/kg) dissolved in $1 \%$ CMC for 15 consecutive days;

- Group 4 received indomethacin in 1\% CMC as in Group 2 and additionally received a suspension of quercetin ( $50 \mathrm{mg} / \mathrm{kg}$ body weight) in $1 \%$ CMC for 15 consecutive days.

\section{Chemicals}

Indomethacin (Sigma, Aldrich) was dissolved in $1 \%$ sodium CMC to prepare a solution. After the animals had been fasted for $24 \mathrm{~h}$ but with free access to tap water, they were administered $1 \mathrm{~mL}$ of this solution orally ( $30 \mathrm{mg} / \mathrm{kg}$ body weight) for 2 consecutive days to induce acute gastric ulcer [3].

Famotidine tablets (Famotidine was purchased from Medical Union Pharmaceutical [MUP] Company, Abou Sultan - Ismailia, Egypt.) were crushed and dissolved in a small volume of CMC. Then $1 \mathrm{~mL}$ of this solution was administered to the animals by orogastric gavage (Famotidine was $50 \mathrm{mg} / \mathrm{kg}$ administered as suspension $1 \%$ sodium CMC [ $2 \mathrm{~mL}$, oral] once daily for 15 consecutive days.), starting from $6 \mathrm{~h}$ after the final indomethacin administration $[36,58]$.

Quercetin (Sigma, Aldrich, Germany) was suspended in $1 \%$ sodium CMC immediately before its administration by orogastric gavage. A dose of $50 \mathrm{mg} / \mathrm{kg}$ body weight was administered to the animals daily for 15 consecutive days, starting from $6 \mathrm{~h}$ after indomethacin administration [45].

\section{Measurement of gastric juice volume and acidity}

On the last day of the experimental period, all the rats were fasted for 12-14 $\mathrm{h}$ and were allowed to have access to only drinking water. The abdomen was incised after scarification by ether anaesthesia, and both the stomach and duodenum were exposed. A fistula made by a poly-ethane tube was inserted into the stomach via a small incision made in the duodenum and held in place by a ligature around the pylorus. The oesophagus was also clamped to prevent reflux and loss of gastric mucosa. The collected fluid was placed in tubes and centrifuged for $5 \mathrm{~min}$ at $5000 \mathrm{rpm}$, and the 
volume of the supernatant was expressed as $\mathrm{mL} / 100 \mathrm{~g}$ body weight. The acid output was determined by titrating with $0.01 \mathrm{NNaOH}$ using phenolphthalein as an indicator and was expressed as $\mu \mathrm{Eq} / 6 \mathrm{~h}$ as output. The volume of gastric juice was measured by a graduated cylinder and expressed in $\mathrm{mL}$ [55].

\section{Macroscopic and ulcer index study}

The stomach of the rats was opened longitudinally, spread out, pinned, and washed with saline. The lesions in the mucosa were examined under a $10 \times$ magnifying glass to assess the ulcer formation, and the number and severity of the ulcers per stomach (see below). Digital images were taken for the whole stomach of each animal to serve as a permanent record. Lesions of the mucosa ranging from hyperaemia at one extreme, through haemorrhagic lesions, and up to full erosions at the other extreme were recorded. The ulcer index of each animal was calculated by using the following scoring system [45]:

- $0=$ normal coloured stomach;

$-0.5=$ red coloration;

- 1 = spot ulceration;

- 1.5 = haemorrhagic streaks;

$-2=$ ulcers between 3 and $5 \mathrm{~mm}$ in greatest dimension;

- $3=$ ulcers greater than $5 \mathrm{~mm}$ in greatest dimension;

$-4=$ perforations.

The mean ulcer score for each animal was expressed as the ulcer index. The effectiveness of the two treatments (famotidine and quercetin) was then calculated as a curative ratio using the following equation: Curative ratio $(C R)=(L C-L T / L C) \times 100$, where $L C$ is the ulcer index in rats treated solely with indomethacin and LT is the ulcer index in rats treated with indomethacin along with a therapeutic treatment (either famotidine or quercetin) [55].

\section{Measurement of gastric enzyme activity}

The activities of the enzymes, i.e., gastric-reduced glutathione (GSH), superoxide dismutase (SOD) and catalase (CAT), in rat stomach tissues were determined. For each biochemical estimation, $0.5 \mathrm{~g}$ of the whole gastric tissue sample was taken and ground with liquid nitrogen in a mortar. The ground tissues were then treated with $4.5 \mathrm{~mL}$ of the appropriate buffer (such as Tris-HCl buffer or phosphate buffer). The mixtures were homogenised on ice using an Ultra-Turrax homogeniser for $15 \mathrm{~min}$. The homogenates were then used for determining the enzymatic activities. All assays were carried out at the room temperature in triplicates [25].

Determination of GSH. The mucosal surface of the stomach was collected by scraping, and then weighed and homogenised in $2 \mathrm{~mL}$ of $50 \mathrm{mM}$ Tris- $\mathrm{HCl}$ buffer containing $20 \mathrm{mM}$ EDTA and $0.2 \mathrm{mM}$ sucrose ( $\mathrm{pH}$ 7.5). Then the homogenate was immediately precipitated with $0.1 \mathrm{~mL}$ of ice-cold $25 \%$ trichloroacetic acid, centrifuged at $4000 \mathrm{rpm}$ for $40 \mathrm{~min}$ at $4^{\circ} \mathrm{C}$. The supernatant was used for the determination of GSH levels. Absorption was measured at $412 \mathrm{~nm}$ using a spectrophotometer. The GSH levels in the gastric mucosa were expressed as nmol/mg tissue [18].

Assay of SOD. The SOD was estimated based on the generation of superoxide radicals produced by xanthine and xanthine oxidase, which react with nitro blue tetrazolium to form Formosan dye. The SOD activity was then measured at $560 \mathrm{~nm}$ by the degree of inhibition of this reaction and was expressed as $\mathrm{mmol} / \mathrm{min} / \mathrm{mg}$ tissue [12].

Assay of CAT. The decomposition of $\mathrm{H}_{2} \mathrm{O}_{2}$ was carried out in the presence of CAT at $240 \mathrm{~nm}$. The CAT activity was defined as the amount of enzyme required to decompose $1 \mathrm{nmol}$ of $\mathrm{H}_{2} \mathrm{O}_{2}$ per minute, at $25^{\circ} \mathrm{C}$ and $\mathrm{pH} 7.8$. The stomach tissues were homogenised in a potassium phosphate buffer solution (0.05 $\mathrm{M}$; $\mathrm{pH}$ 7.4) and then centrifuged at $3215 \mathrm{rpm}$ for $15 \mathrm{~min}$. A hydrogen peroxide solution $(0.05 \mathrm{M})$ was prepared with potassium phosphate buffer, and the substrate solution for the assay. A volume of $0.1 \mathrm{~mL}$ of the supernatant was mixed with $1.9 \mathrm{~mL}$ of phosphate buffer solution, and the absorbance decline was measured at $240 \mathrm{~nm}$. The results were expressed as $\mathrm{mmol} / \mathrm{min} / \mathrm{mg}$ tissue [50].

\section{Histological study}

The specimens from the stomachs of all rats were fixed in $10 \%$ formalin and were then processed to form paraffin blocks. Serial sections of $5 \mu \mathrm{m}$ in thickness were prepared and subjected to routine haematoxylin and eosin (H\&E) staining [7].

\section{Statistical analysis}

All the results were expressed as mean \pm standard error of the mean (SEM). The t-test for comparison between groups and one-way analysis of variance (ANOVA) for multi-sample groups at $p<0.05$ were used to assess statistical significance in various groups of animals by using SPSS program version 2.01 (SPSS, 2008, UK). 


\section{Biological activities}

Antioxidant. A diet rich in flavonoids reduces the risk for oxidative-stress related chronic diseases such as asthma [35], diabetes [2], coronary heart disease [28], lung cancer [71], and stroke [49]. Antioxidation could be a result of metal chelation [4], scavenging of radicals [68], enzyme inhibition [56], and/or induction of the expression of protective enzymes [46].

Within the flavonoid family, quercetin is the most potent scavenger for reactive oxygen species (ROS), including $\mathrm{O}_{2}$ [15], and reactive nitrogen species (RNS) like nitric oxide [8], and ONOO [29]. Quercetin has been shown to be an excellent in vitro antioxidant activity [62].

Anti-inflammatory. Cyclooxygenase and lipoxygenase play an important role as inflammatory mediators. They are involved in the release of arachidonic acid, which is a starting point for a general inflammatory response. Quercetin is known to possess strong anti-inflammatory capacities [27].

Quercetin's anti-inflammatory activity appears to be due to its antioxidant and inhibitory effects on inflammation-producing enzymes (cyclooxygenase, and lipoxygenase) and the subsequent inhibition of inflammatory mediators, including leukotrienes and prostaglandins [9].

Antiulcer effects. Quercetin has been shown to have antiulcer and gastroprotective effects [16]. An interesting aspect of quercetin's anti-ulcer effect is that it has been shown to inhibit growth of $H$. pylori in a dose-dependent manner in vitro [59].

It was reported that quercetin inhibits oxidative damage in ethanol-induced gastric lesions of rats [31].

It was found that the oral use of quercetin before and after administration of diclofenac sodium has been shown to be associated with fewer ulcers in test animals [74].

With oral administration to mice and rats, quercetin consistently did not induce any significant changes in several mutagenicity/genotoxicity endpoints (i.e., micronuclei, chromosomal aberrations, sister chromatid exchange, unscheduled DNA synthesis, and alkali-labile DNA damage) in somatic cells in comparison to untreated controls. Quercetin has been studied for its potential carcinogenicity in numerous long-term experimental animal studies, the majority of which indicated no evidence of significantly increased incidences of neoplasm formation related to its oral administration. Human studies have failed to show any adverse effects associated with the oral administration of quercetin in a single dose of up to $4 \mathrm{~g}$ or after 1 month of $500 \mathrm{mg}$ twice daily [54].

Organs weight analysis hearts, lungs, livers, spleens, and kidneys of the sacrificed rats were carefully removed, washed with saline solution, dried with filter paper, and weighed independently. The relative organs weight was calculated as previously described (Chapman et al., 1959) using the following equation: Relative organ's weight: Organ weight $=$ Total body weight/100 [10].

\section{RESULTS}

\section{Macroscopic examination (Fig. 1; Table 1)}

The gross examination of the stomach lining of the control rats showed that the mucosa had a whitish colour with prominent rugae. However, the examination of the mucosal lining in indomethacintreated rats revealed haemorrhages or linear breaks/ erosions to the mucosal surface. In addition, the ulcer index in the rats of this treated group was very high, with an average of $40.52 \pm 0.73 \mathrm{~mm}$. This confirms the effectiveness of the treatment in inducing peptic ulcers. However, indomethacin-treated rats who had additionally received either famotidine or quercetin showed fewer hyperaemic areas and linear brown lesions. The ulcer index for the rats treated with famotidine was $27.3 \pm 0.66 \mathrm{~mm}$, which is significantly lower than that of the group treated with indomethacin alone $(p<0.05)$. The rats treated with quercetin showed an ulcer index of only $19.55 \pm$ $\pm 0.62 \mathrm{~mm}$, which was significantly lower than all the other indomethacin-treated groups $(p<0.05)$. Thus, it is clear that the treatment of animals with quercetin produced more effective protection against gastric ulcers compared to the treatment with famotidine.

\section{Biochemical studies}

Gastric juice volume. The volume of gastric juice obtained from rats with indomethacin-induced gastric ulcer (control + ve) untreated ulcer group was substantially greater than that in normal control rats $(0.8 \pm 0.14 \mathrm{~mL}$ compared with $0.26 \pm 0.05 \mathrm{~mL}$ ) (Table 2). Comparatively, indomethacin-treated rats that also received either quercetin or famotidine did not exhibit any increase in the volume of gastric juice $(0.22 \pm 0.15$ and $0.30 \pm 0.42$, respectively) compared to control animals.

Gastric juice $\mathrm{pH}$. The $\mathrm{pH}$ of gastric juice was found to be reduced in indomethacin-treated rats (mean $3.07 \pm 0.58)$ compared with that of the normal rats (4.57 \pm 0.24$)$ (Table 2). However, indomethacin-treated rats who also received quercetin had $\mathrm{pH}$ values similar to 

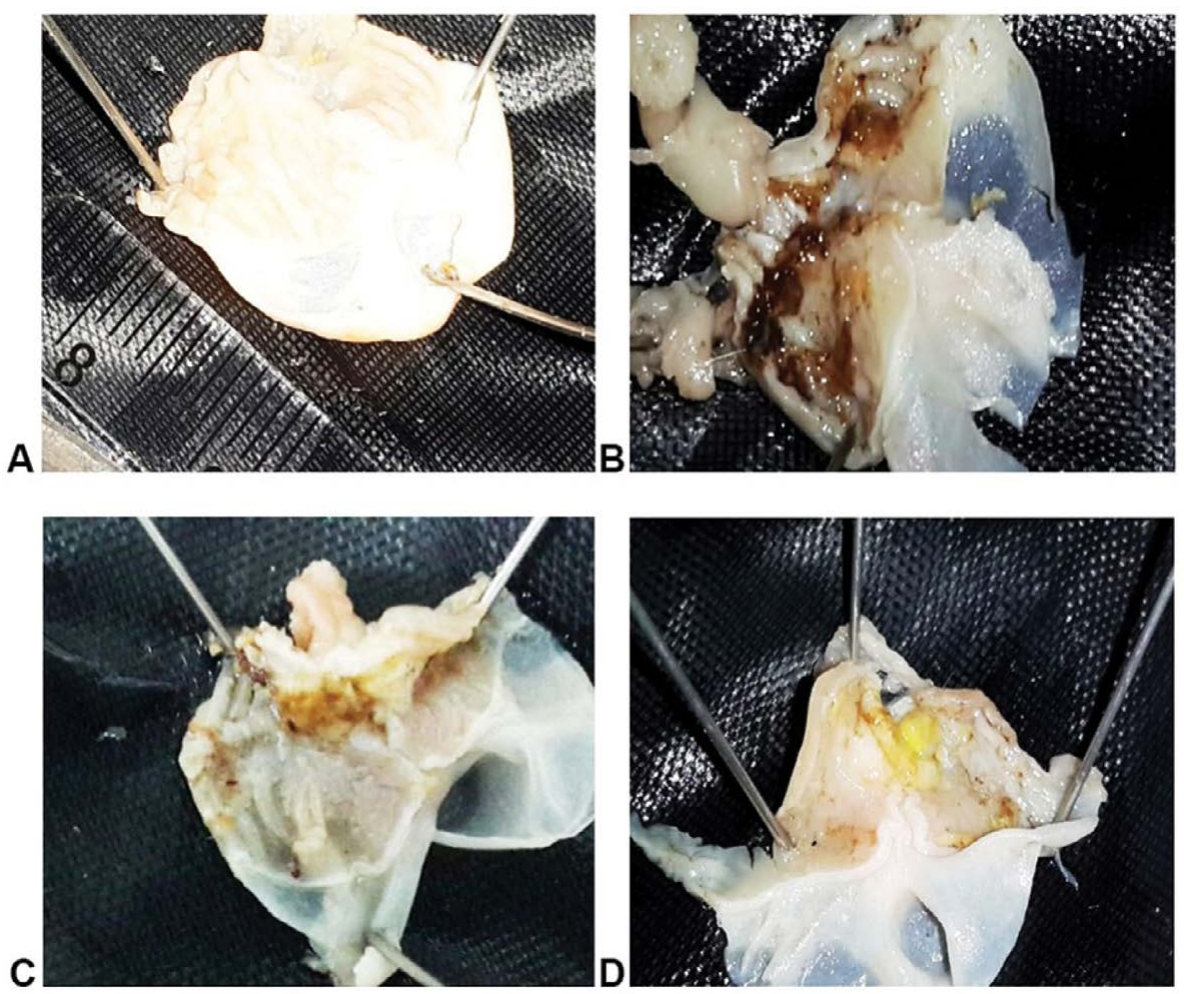

Figure 1. Gastric mucosa appearance in stomachs of control group (A), indomethacin-induced ulcer group (B), famotidine-treated group (C), and quercetin-treated group (D).

Table 1. Effect of different treatments on indomethacin-induced ulcers

\begin{tabular}{lcc}
\hline Group & Ulcer index \pm SEM [mm] & Curative ratio [\%] \\
\hline Control & 0 & - \\
Indomethacin (I) & $40.5 \pm 0.7$ & - \\
I + famotidine & $27.3 \pm 0.7^{*}$ & 32.6 \\
I + quercetin & $19.5 \pm 0.6^{* *}$ & 51.7 \\
\hline
\end{tabular}

All values are expressed as mean \pm standard error of the mean (SEM), $n=10$ animals in each group. There are significant differences between rats treated with famotidine or quercetin and those treated with indomethacin alone $(p<0.05)$

*Significant difference between famotidine group (llb) vs. indomethacin-treated group (lla) $p<0.05$. * Highly significant difference between quercetin-treated group (IIc) vs. indomethacin-treated group (lla), $\mathrm{p}<0.05$

Table 2. Effect of different treatments on the volume and $\mathrm{pH}$ of the gastric juice (mean $\pm S E M, \mathrm{~mL}$ )

\begin{tabular}{|c|c|c|}
\hline Group & $\begin{array}{l}\text { Gastric juice volume } \\
\text { (mean } \pm \text { SEM; mL) }\end{array}$ & $\begin{array}{l}\text { Gastric juice pH } \\
\text { (mean } \pm \text { SEM) }\end{array}$ \\
\hline Control & $0.26 \pm 0.1$ & $4.6 \pm 0.2$ \\
\hline Indomethacin (I) & $0.8 \pm 0.1$ & $3.1 \pm 0.6$ \\
\hline I + famotidine & $0.22 \pm 0.1^{* *}$ & $5.5 \pm 0.2^{*}$ \\
\hline I + quercetin & $0.30 \pm 0.4^{*}$ & $4.6 \pm 0.01^{* *}$ \\
\hline
\end{tabular}

Table 3. Effects of different treatments on the level of glutathione and various enzymes in different experimental groups

\begin{tabular}{lccc}
\hline Group & GSH $[\mu \mathrm{mol} / \mathrm{L}]$ & SOD $[\mathrm{U} / \mathrm{mL}]$ & CAT $[\mu \mathrm{mol} / \mathrm{L}]$ \\
\hline $\mathrm{I}$ & $4.05 \pm 0.06$ & $44.06 \pm 0.6$ & $229.30 \pm 2.7$ \\
$\mathrm{lla}$ & $1.01 \pm 0.02$ & $21.80 \pm 0.4$ & $101.20 \pm 2.2$ \\
$\mathrm{llb}$ & $2.32 \pm 0.03$ & $28.80 \pm 0.60^{*}$ & $156.85 \pm 3.6^{*}$ \\
$\mathrm{llc}$ & $3.38 \pm 0.04$ & $37.2 \pm 0.65^{* *}$ & $199.58 \pm 4.1^{* *}$ \\
\hline
\end{tabular}

GSH - glutathione; SOD — superoxide dismutase; CAT — catalase

All values are expressed as mean \pm standard error of the mean, $n=10$ animals in each group.

${ }^{*}$ Significant difference between famotidine group (llb) vs. indomethacin treated group (lla), $p<0.05$. ${ }^{*}$ Highly significant difference between quercetin-treated group (IIc) vs. indomethacin-treated group (lla), $\mathrm{p}<0.05$.

that of the controls. The $\mathrm{pH}$ values of those rats who received famotidine were even less acidic $(5.52 \pm 0.21)$.

Levels of gastric enzyme activity. The antioxidant markers GSH, SOD and CAT were found to be significantly decreased in the indomethacin-treated group when compared with the control group. However, those indomethacin-treated rats that were subsequently treated with either famotidine or quercetin had levels of antioxidant markers closer to that of the normal group and significantly higher than those of rats treated with indomethacin alone (Table 3). 


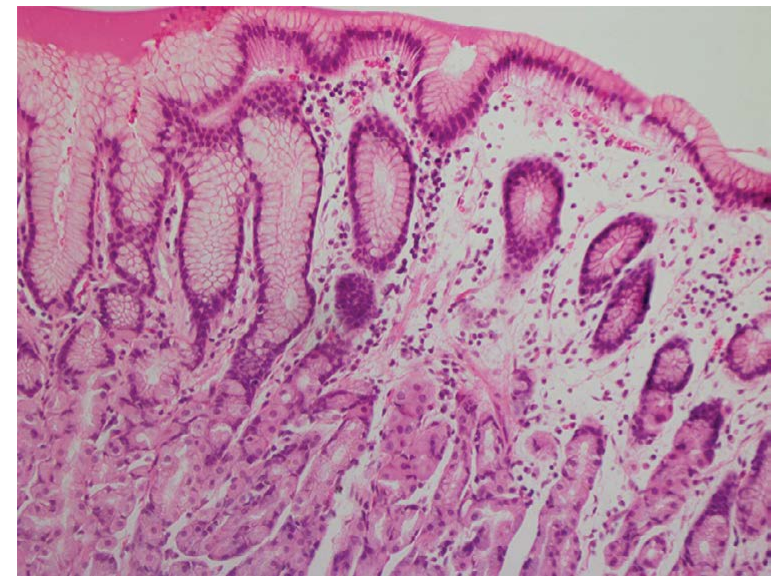

Figure 2. Fundus of a normal rat from the control group. The lamina propria contained blood vessels and smooth muscle fibres (H\&E staining, $\times 100$ ).

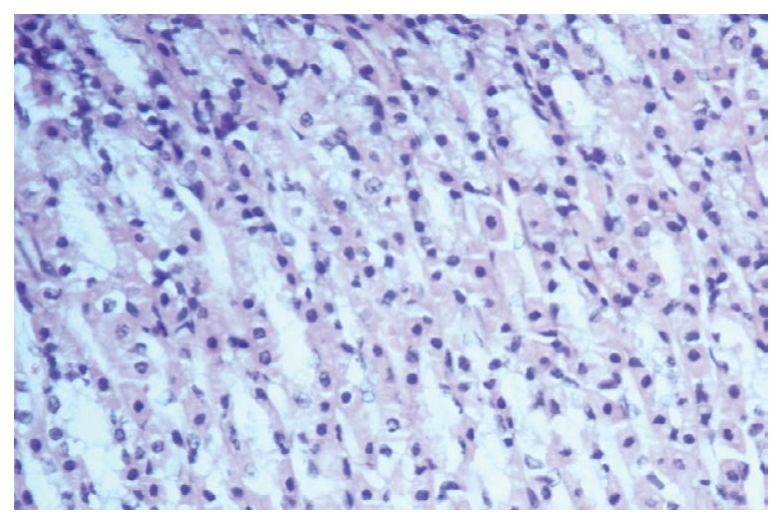

Figure 3. A section of the stomach fundus of a rat from control group showing surface columnar mucous cells (H\&E staining, $\times 400$ ).

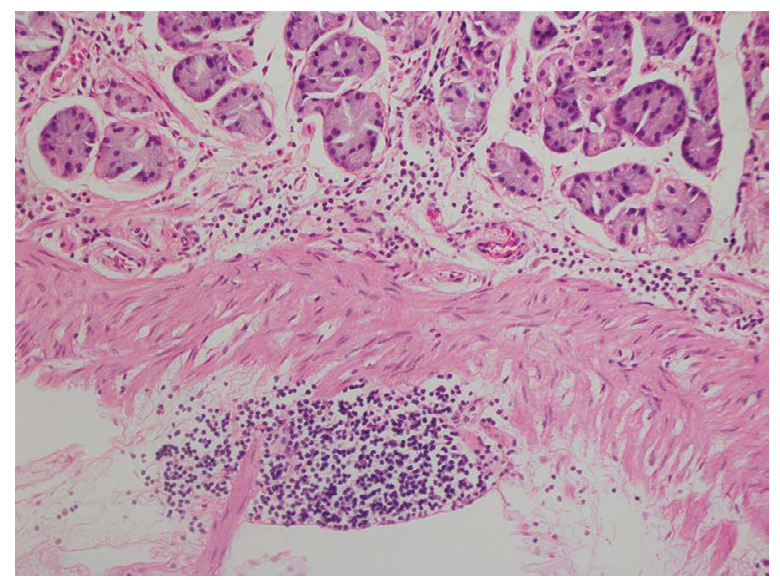

Figure 4. A section of the fundus of an indomethacin-treated rat (H\&E staining, $\times 400$ ).

\section{Histological results}

The H\&E-stained sections of the stomachs of control rats showed normal histology of the gastric

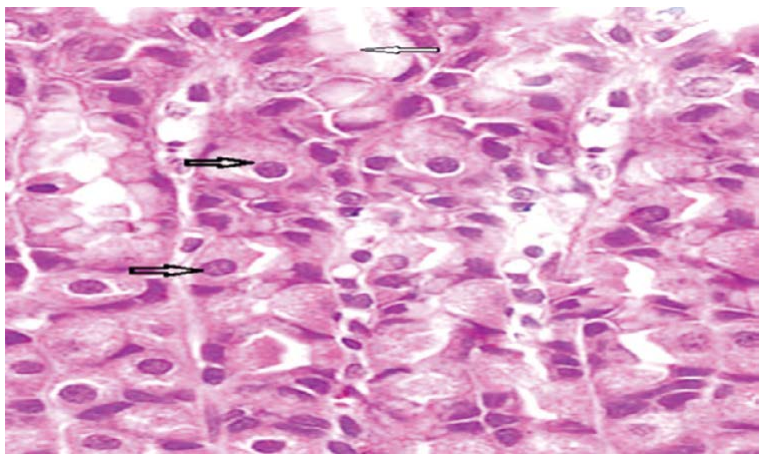

Figure 5. A section of the stomach of a rat from the famotidine-treated group (H\&E staining, $\times 100)$.

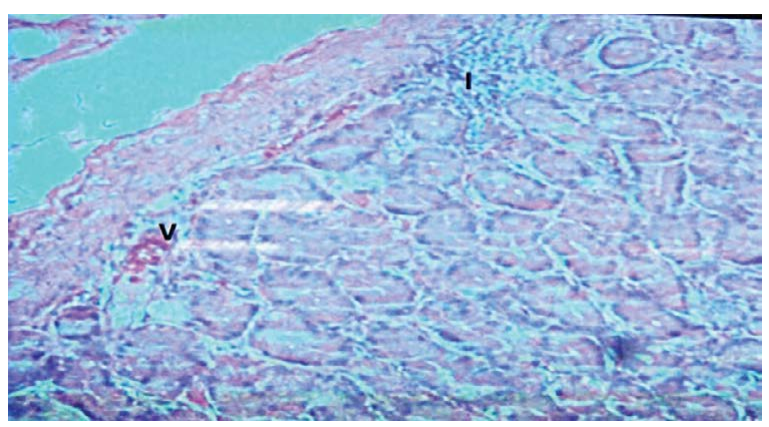

Figure 6. A photomicrograph of a section of the fundus of a rat from the quercetin-treated group showing normal gastric mucosa with some inflammatory cells (I) and congested blood vessels (V) in the lamina propria (H\&E staining, $\times 100$ ).

mucosa. The gastric glands were found to be narrow, tightly packed, straight, and perpendicular to the surface epithelium, occupying the whole thickness of the lamina propria. The lamina propria contained blood vessels and smooth muscle fibres (Fig. 2). The glands contained mucous cells (columnar with pale cytoplasm), parietal cells (central rounded nuclei) and chief cells in the basal region (columnar with basal oval nuclei, basal basophilic cytoplasm, and pale apical region) (Fig. 3). The resulting mucosal lesions in indomethacin-treated rats showed superficial damage with a distorted shape of the gastric glands. The cells lining the damaged glandular area appeared to be shrunken with deeply acidophilic cytoplasm. The basal part of the gland showed loss of architecture and inflammatory cells in the lamina propria with dilated and congested capillaries (Fig. 4).

The H\&E-stained sections in famotidine-treated rats showed deep eosinophilic cytoplasmic epithelial cells with vacuolisation of some cells and an increase in mucus-secreting cells with inflammatory cells in the lamina propria and widened gastric pits (Fig. 5). 
In quercetin-treated rats, the gastric mucosa was found to be similar to the control group with some inflammatory cells and congested blood vessels in the lamina propria (Fig. 6).

\section{DISCUSSION}

Flavonoids are a group of naturally occurring compounds that are widely distributed as secondary metabolites in the plant kingdom. Quercetin, a flavonoid, prevents oxidant injury and cell death using several mechanisms, such as scavenging oxygen radicals [1]. The present study assessed the effects of quercetin on gastric ulceration induced by indomethacin in adult male albino rats. Like other NSAIDs, indomethacin is an analgesic that exhibits side effects such as ulcerogenic action on stomach [40].

Quercetin's anti-inflammatory activity appears to be due to its antioxidant and inhibitory effects on inflammation-producing enzymes (cyclooxygenase, lipoxygenase) and the subsequent inhibition of inflammatory mediators, including leukotrienes and prostaglandins [34]. Inhibition of histamine release by mast cells and basophiles also contribute to quercetin's anti-inflammatory activity [33].

In the present study, we observed various macroscopic changes in the gastric mucosa. Normal white gastric mucosal rugae with a reduction in ulcer index were observed in both the control group and indomethacin-treated rats who also received quercetin. Contrarily, severe redness of the mucosa with brown haemorrhagic patches and a very high ulcer index were observed in those rats treated with indomethacin alone. These findings are similar to previous reports [65] in which the redness was attributed to vasodilatation and congestion of blood vessels, and the brown colorations were due to the effect of $\mathrm{HCl}$ on the haemorrhagic lesions.

The biochemical results showed that the volume of gastric secretion and its acidity were increased and the gastric enzymes were significantly decreased in indomethacin-treated rats compared with the control group. These results are in agreement with the findings of Seckin et al. [57]. Moreover, we also observed the destruction of the mucosal epithelial cells as well as a highly eosinophilic cytoplasm and pyknotic nuclei along the length of fundic glands from the neck to the base. This is in agreement with the study of Drăghia [17], which reported a decrease in oxidative activity in the surface epithelium and vascular endothelium. NSAIDs, such as indomethacin, produce beneficial effects through their ability to block cyclooxygenase, thereby inhibiting prostaglandin production [23]. Decreased prostaglandin level contributes to the pathogenesis of gastroduodenal mucosal ulcerations [26]. In addition, mucosal lesions due to NSAID-induced gastrointestinal damage are associated with an increase in ROS such as superoxide radical anions and hydroxyl radicals [64]. These mechanisms, including those related to prostaglandin suppression, lead to microvessel occlusion and subsequent hyper-production of reactive oxygen metabolites. In particular, indomethacin causes gastric erosions with increased lipid peroxidation and decreased glutathione peroxidase activity [47]. The presence of superoxide anions ( $\mathrm{O2}^{-}$) may be responsible for the gastric damage as well as other tissue damage. Therefore, many researchers have focused on oxygenderived free radicals. This mechanism, in combination with ROS, damages membrane proteins by inducing lipid peroxidation and attacking unsaturated fatty acids [24]. Therefore, antioxidant defence systems and their components, including antioxidant enzymes, foods, and drugs, are considered to be important in preventing the toxic and disease-causing effects of oxygen-derived free radicals. Oxygen-handling cells have antioxidant enzymes that can protect them [66].

Both famotidine and quercetin treatments restored the gastric mucosa to near normality. However, the famotidine-treated rats had inflammatory cells infiltration with congested blood vessels in their lamina propria, whereas the quercetin-treated rats had an increase in surface mucous cells due to the increase in the apical cytoplasmic content of mucus granules. In addition, a widening of the gastric pits with increased mucus secretion was also observed. The histological results of the indomethacin group were confirmed by that of Fawcett's [22] study, which reported an apparent increase in mucin in stomachs in which most of the surface mucous cells were filled with rounded mucoid granules. The role of gastric mucins has been widely explained as forming a barrier between the surface epithelial cells and gastric juices; mucus may have the ability to resist enzymatic hydrolysis due to its carbohydrate moieties. Acidic mucin may have a role in protecting the pit cells against the effect of $\mathrm{HCl}$ during its passage. The alternating layers of neutral and acidic mucins in the surface coat act as a safeguard against $\mathrm{HCl}$ and other digestive enzymes in the lumen [70].

Studies have shown that some of the altered cells lack the ability to recover [5]. In this study group, 
the treatment with indomethacin led to the loss of architecture and vacuolation of cells while the quercetin treatment resulted in a normal mucosa except for an increase in mucus granules in surface mucus cells. Quercetin exerts antioxidant influences by several mechanisms; these include scavenging oxygen radicals, protecting against lipid peroxidation, and chelating metal ions [37]. The high antioxidant activity of quercetin may be attributed to its capacity to diffuse through the cell membrane at a high rate [32]. Quercetin induces a decrease in the proinflammatory cytokines [30]. Gastric mucosa can be repaired after mucosal injury by mucosal restitution and reepithelisation by sloughing off the damaged cells. This is achieved by rapid migration of viable stem cells to the injured site to replace the dead cells during ulcer healing [13]. However, human studies have failed to show any adverse effects associated with the oral administration of quercetin in a single dose of up to $4 \mathrm{~g}$ or after 1 month of $500 \mathrm{mg}$ twice daily [54].

One of the limitation of this study is that quercetin has been studied for its potential carcinogenicity in numerous long-term experimental animal studies, the majority of which indicated no evidence of significantly increased incidences of neoplasm formation related to its oral administration.

\section{CONCLUSIONS}

Quercetin has effective anti-ulcer activity against indomethacin-induced ulcerogenesis, and it can be used for therapy of ulcerogenesis and gastric mucosal injury. In particular, patients treated with NSAIDs may benefit from the consumption of a quercetin-rich diet.

\section{Acknowledgements}

Mohamed Abdelwahab Abo rehab, Assistant prof. Pharmaceutics Departments, Faculty of Pharmacy, Umm Al-Qura University, Saudi Arabia — for his help in quercetin preparation.

Eman Mohammed Faruk, Department of Histology and Cell Biology, Benha Faculty of Medicine, Egypt for her valuable comments on this article.

\section{REFERENCES}

1. Abrahamse S, Kloots W, Amelsvoort Jv. Absorption, distribution, and secretion of epicatechin and quercetin in the rat. Nutr Res. 2005; 25(3): 305-317, doi: 10.1016/j. nutres.2004.10.013.

2. Aguirre L, Arias N, Macarulla MT, et al. Beneficial Effects of Quercetin on Obesity and Diabetes. The Open Nutraceuticals J. 2011; 4: 189-198, doi:10.2174/1876396001 104010189.
3. Alqasoumi S, Al-Sohaibani M, Al-Howiriny T, et al. Rocket. World J Gastroenterol. 2009; 15(16): 1958-1965, indexed in Pubmed: 19399927.

4. Amić $D$, Davidović-Amić $D$, Beslo $D$, et al. SAR and QSAR of the antioxidant activity of flavonoids. Curr Med Chem. 2007; 14(7): 827-845, indexed in Pubmed: 17346166.

5. Asar M, Kayişli UA, Izgüt-Uysal VN, et al. Cadmiuminduced changes in epithelial cells of the rat stomach. Biol Trace Elem Res. 2000; 77(1): 65-81, indexed in Pubmed: 11097472.

6. Asefa Z, G/eyesus A. Perforated peptic ulcer disease in Zewditu Hospital. Ethiop Med J. 2012; 50(2): 145-151, indexed in Pubmed: 22924283.

7. Bancroft JD, Gamble M. Theory and practice of histological techniques. Churchill Livingstone, London 2007.

8. Boots AW, Haenen GR, Bast A. Health effects of quercetin: from antioxidant to nutraceutical. Eur J Pharmacol. 2008; 585(2-3): 325-337, doi:10.1016/j.ejphar.2008.03.008, indexed in Pubmed: 18417116.

9. Brett $A$, Ghica ME. Electrochemical Oxidation of Quercetin. Electroanalysis. 2003; 15(22): 1745-1750, doi: 10.1002/ elan. 200302800.

10. Chapman DG, Castillo R, Campbell JA. Evaluation of protein in foods: 1 . A method for the determination of protein efficiency ratios. Can J Biochem Phys. 1959; 37(5): 679-686, doi: 10.1139/o59-074.

11. Chason RD, Reisch JS, Rockey DC. More favorable outcomes with peptic ulcer bleeding due to Helicobacter pylori. Am J Med. 2013; 126(9): 811-818.e1, doi: 10.1016/j. amjmed.2013.02.025, indexed in Pubmed: 23830535.

12. Chatterjee A, Chatterjee S, Biswas A, et al. Gallic Acid Enriched Fraction of Phyllanthus emblica Potentiates IndomethacinInduced Gastric Ulcer Healing via e-NOS-Dependent Pathway. Evid Based Complement Alternat Med. 2012; 2012: 487380, doi: 10.1155/2012/487380, indexed in Pubmed: 22966242.

13. Coşkun O, Kanter M, Armutçu F, et al. Protective effects of quercetin, a flavonoid antioxidant in absolute ethanolinduced acute gastric ulcer. Eur J Gen Med. 2004; 1: 37-42.

14. Cotelle N. Role of flavonoids in oxidative stress. Curr Top Med Chem. 2001; 1(6): 569-590, indexed in Pubmed: 11895132.

15. Cushnie T, Lamb A. Antimicrobial activity of flavonoids. Int J Antimicrob Agents. 2005; 26(5): 343-356, doi: 10.1016/j. ijantimicag.2005.09.002.

16. Sánchez de Medina F, Gálvez J, González M, et al. Effects of quercetin on epithelial chloride secretion. Life Sci. 1997; 61(20): 2049-2055, indexed in Pubmed: 9366512.

17. Drăghia AC. Histochemical and histopathological study of the gastric mucosa in the portal hypertensive gastropathy. Rom J Morphol Embryol. 2006; 47(3): 259-262, indexed in Pubmed: 17308685.

18. Dursun H, Bilici M, Albayrak F, et al. Antiulcer activity of fluvoxamine in rats and its effect on oxidant and antioxidant parameters in stomach tissue. BMC Gastroenterol. 2009; 9: 36, doi: 10.1186/1471-230X-9-36, indexed in Pubmed: 19457229.

19. Erlund I. Review of the flavonoids quercetin, hesperetin, and naringenin. Dietary sources, bioactivities, bioavailability, and epidemiology. Nutr Res. 2004; 24(10): 851-874, doi: 10.1016/j.nutres.2004.07.005.

20. Ertem D. Clinical practice: Helicobacter pylori infection in childhood. Eur J Pediatr. 2013; 172(11): 1427-1434, 
doi: 10.1007/s00431-012-1823-4, indexed in Pubmed: 23015042.

21. Farombi EO. Genotoxicity of chloroquine in rat liver cells: protective role of free radical scavengers. Cell Biol Toxicol. 2006; 22(3): 159-167, doi:10.1007/s10565-006-0173-2, indexed in Pubmed: 16532284.

22. Fawcett DW. The Cell. W.B. Saunders Co, Philadelphia 1981.

23. Fiorucci S, Antonelli E, Morelli A. Mechanism of nonsteroidal anti-inflammatory drug-gastropathy. Dig Liver Dis. 2001; 33 Suppl 2: S35-S43, indexed in Pubmed: 11827361.

24. Fornai M, Natale G, Colucci R, et al. Mechanisms of protection by pantoprazole against NSAID-induced gastric mucosal damage. Naunyn Schmiedebergs Arch Pharmacol. 2005; 372(1): 79-87, doi: 10.1007/s00210-005-1075-1, indexed in Pubmed: 16080005.

25. Freitas FF, Fernandes HB, Piauilino CA, et al. Gastroprotective activity of Zanthoxylum rhoifolium Lam. in animal models. J Ethnopharmacol. 2011; 137(1): 700-708, doi: 10.1016/j.jep.2011.06.026, indexed in Pubmed: 21723384.

26. Genta RM. Differential diagnosis of reactive gastropathy. Semin Diagn Pathol. 2005; 22(4): 273-283, indexed in Pubmed: 16939055.

27. Geraets L, Moonen HJJ, Brauers K, et al. Dietary flavones and flavonoles are inhibitors of poly(ADP-ribose)polymerase-1 in pulmonary epithelial cells. J Nutr. 2007; 137(10): 2190-2195, indexed in Pubmed: 17884996.

28. Gross M. Flavonoids and Cardiovascular Disease. Arch Physiol Biochem. 2004; 42(s1): 21-35, doi: 10.1080/138802 00490893483.

29. Heijnen CG, Haenen GR, van Acker FA, et al. Flavonoids as peroxynitrite scavengers: the role of the hydroxyl groups. Toxicol In Vitro. 2001; 15(1): 3-6, indexed in Pubmed: 11259863.

30. Jackson JK, Higo T, Hunter WL, et al. The antioxidants curcumin and quercetin inhibit inflammatory processes associated with arthritis. Inflamm Res. 2006; 55(4): 168-175, doi: 10.1007/s00011-006-0067-z, indexed in Pubmed: 16807698

31. Kahraman A, Erkasap N, Köken T, et al. The antioxidative and antihistaminic properties of quercetin in ethanolinduced gastric lesions. Toxicology. 2003; 183(1-3): 133-142, indexed in Pubmed: 12504347.

32. Kanter M, Aktas C, Erboga M. Protective effects of quercetin against apoptosis and oxidative stress in streptozotocin-induced diabetic rat testis. Food Chem Toxicol. 2012; 50(3-4): 719-725, doi: 10.1016/j.fct.2011.11.051, indexed in Pubmed: 22166789.

33. Kelly GS. Quercetin. Monograph. Altern Med Rev. 2011; 16(2): 172-194, indexed in Pubmed: 21649459.

34. Kim HP, Mani I, Iversen L, et al. Effects of naturally-occurring flavonoids and biflavonoids on epidermal cyclooxygenase and lipoxygenase from guinea-pigs. Prostaglandins Leukot Essent Fatty Acids. 1998; 58(1): 17-24, indexed in Pubmed: 9482162.

35. Knekt $P$, Kumpulainen J, Järvinen $R$, et al. Flavonoid intake and risk of chronic diseases. Am J Clin Nutr. 2002; 76(3): 560-568, indexed in Pubmed:12198000.
36. Kumar V, Bhat ZA, Kumar D, et al. Gastroprotective effect of leaf extracts of Basella alba var. alba against experimental gastric ulcers in rats. Rev Bras Farmacogn. 2012; 22(3): 657-662, doi: 10.1590/s0102-695x2012005000032.

37. Lakhanpal P, Rai DK. Quercetin: A Versatile Flavonoid. Int J Med Update. 2007; 2(2), doi: 10.4314/ijmu.v2i2.39851.

38. Lima CF, Fernandes-Ferreira M, Pereira-Wilson C. Phenolic compounds protect HepG2 cells from oxidative damage: relevance of glutathione levels. Life Sci. 2006; 79(21): 2056-2068, doi: 10.1016/j.Ifs.2006.06.042, indexed in Pubmed: 16857214.

39. Liu JL, Du J, Fan LL, et al. Effects of quercetin on hyperproliferation of gastric mucosal cells in rats treated with chronic oral ethanol through the reactive oxygen speciesnitric oxide pathway. World J Gastroenterol. 2008; 14(20): 3242-3248, indexed in Pubmed: 18506933.

40. Malfertheiner P, Chan F, McColl K. Peptic ulcer disease. The Lancet. 2009; 374(9699): 1449-1461, doi: 10.1016/ s0140-6736(09)60938-7.

41. Mamani-Matsuda M, Kauss T, Al-Kharrat A, et al. Therapeutic and preventive properties of quercetin in experimental arthritis correlate with decreased macrophage inflammatory mediators. Biochem Pharmacol. 2006; 72(10): 1304-1310, doi: 10.1016/j.bcp.2006.08.001, indexed in Pubmed:16959220.

42. Milosavljevic T, Kostić-Milosavljević M, Jovanović I, et al. Complications of peptic ulcer disease. Dig Dis. 2011; 29(5): 491-493, doi:10.1159/000331517, indexed in Pubmed: 22095016.

43. Mira L, Fernandez MT, Santos M, et al. Interactions of flavonoids with iron and copper ions: a mechanism for their antioxidant activity. Free Radic Res. 2002; 36(11): 1199-1208, indexed in Pubmed: 12592672.

44. Miyamoto M, Haruma K. [Gastric ulcer and duodenal ulcer]. Nihon Rinsho. 2013; 71(8): 1418-1423, indexed in Pubmed: 23967673.

45. Moghaddam G, Sharifzadeh M, Hassanzadeh G, et al. Anti-Ulcerative Potential of Punica granatum L (Lythraceae) Hydroalcohol Fruit Peel Extract. Trop J Pharm Res. 2014; 13(7): 1093, doi: 10.4314/tjpr.v13i7.12.

46. Myhrstad MCW, Carlsen H, Nordström O, et al. Flavonoids increase the intracellular glutathione level by transactivation of the gamma-glutamylcysteine synthetase catalytical subunit promoter. Free Radic Biol Med. 2002; 32(5): 386-393, indexed in Pubmed: 11864778.

47. Naesdal J, Brown K. NSAID-associated adverse effects and acid control aids to prevent them: a review of current treatment options. Drug Saf. 2006; 29(2): 119-132, indexed in Pubmed: 16454539.

48. Pawlikowska-Pawlega B, Gruszecki WI, Misiak LE, et al. The study of the quercetin action on human erythrocyte membranes. Biochem Pharmacol. 2003; 66(4): 605-612, indexed in Pubmed: 12906925.

49. Perez-Vizcaino F, Duarte J, Jimenez R, et al. Antihypertensive effects of the flavonoid quercetin. Pharmacol Rep. 2009; 61 (1): 67-75, indexed in Pubmed: 19307694.

50. Polat B, Albayrak Y, Suleyman B, et al. Antiulcerative effect of dexmedetomidine on indomethacin-induced gastric ulcer in rats. Pharmacol Rep. 2011; 63(2): 518-526, indexed in Pubmed: 21602607. 
51. Ramakrishnan K, Salinas RC. Peptic ulcer disease. Am Fam Physician. 2007; 76(7): 1005-1012, indexed in Pubmed: 17956071.

52. Repetto MG, Llesuy SF. Antioxidant properties of natural compounds used in popular medicine for gastric ulcers. Braz J Med Biol Res. 2002; 35(5): 523-534, indexed in Pubmed: 12011936.

53. Robaszkiewicz A, Balcerczyk A, Bartosz G. Antioxidative and prooxidative effects of quercetin on A549 cells. Cell Biol Int. 2007; 31(10): 1245-1250, doi: 10.1016/j. cellbi.2007.04.009, indexed in Pubmed: 17583542.

54. Russo M, Spagnuolo C, Tedesco I, et al. The flavonoid quercetin in disease prevention and therapy: facts and fancies. Biochem Pharmacol. 2012; 83(1): 6-15, doi: 10.1016/j. bcp.2011.08.010, indexed in Pubmed: 21856292.

55. Sairam K, Rao CV, Goel RK. Effect of Convolvulus pluricaulis Chois on gastric ulceration and secretion in rats. Indian J Exp Biol. 2001; 39(4): 350-354, indexed in Pubmed: 11491580.

56. Sandhar HK, Kumar B, Prasher S, et al. Review of Phytochemistry and Pharmacology of Flavonoids. Int Pharmaceutica Sciencia. 2011; 1: 25-41.

57. Seckin Y, Harputluoglu MMM, Batcioglu K, et al. Gastric tissue oxidative changes in portal hypertension and cirrhosis. Dig Dis Sci. 2007; 52(5): 1154-1158, doi: 10.1007/ s10620-006-9139-8, indexed in Pubmed: 17345161.

58. Sener G, Paskaloglu K, Ayanoglu-dülger G. Protective effect of increasing doses of famotidine, omeprazole, lansoprazole, and melatonin against ethanol-induced gastric damage in rats. Indian J Pharmacol. 2004; 36: 171-174.

59. Sumbul S, Ahmad MA, Mohd A, et al. Role of phenolic compounds in peptic ulcer: An overview. J Pharm Bioallied Sci. 2011; 3(3): 361-367, doi:10.4103/0975-7406.84437, indexed in Pubmed: 21966156.

60. Surapaneni SR, Reddy AB. The Perforation-Operation Time Interval; An Important Mortality Indicator in Peptic Ulcer Perforation. J Clin Diagn Res. 2013; 7(5): 880-882, doi: 10.7860/JCDR/2013/4925.2965, indexed in Pubmed: 23814733.

61. Tang RS, Chan FKL. Therapeutic management of recurrent peptic ulcer disease. Drugs. 2012; 72(12): 1605-1616, doi: 10.2165/11634850-000000000-00000, indexed in Pubmed: 22867043.

62. Terao J. Dietary Flavonoids as Antioxidants. In: Yoshikawa T (ed.). Food Factors for Health Promotion. Forum Nutr. Karger, Basel 2009: pp. 87-94.

63. Thorsen K, Søreide JA, Søreide K. Epidemiology of perforated peptic ulcer: Age- and gender-adjusted analysis of incidence and mortality. World J Gastroenterol. 2013; 19(3): 347, doi: 10.3748/wjg.v19.i3.347.

64. Toki M, Aoki K, Katsumi N, et al. [NSAID and its effect on prostaglandin]. Nihon Rinsho. 2007; 65(10): 1807-1811, indexed in Pubmed: 17926528.

65. Villegas I, La Casa C, de la Lastra CA, et al. Mucosal damage induced by preferential COX-1 and COX-2 inhibitors: role of prostaglandins and inflammatory response. Life Sci. 2004; 74(7): 873-884, indexed in Pubmed: 14659976.

66. Villegas I, Martín MJ, La Casa C, et al. Effects of oxicam inhibitors of cyclooxygenase on oxidative stress generation in rat gastric mucosa. A comparative study. Free Radic Res. 2002; 36(7): 769-777, indexed in Pubmed: 12180128.

67. Webster-Gandy J, Madden A, Holdsworth M. Oxford handbook of nutrition and dietetics. 2nd ed. Oxford University Press, Oxford 2012.

68. Wiczkowski W, Nèmeth K, Buciński A, et al. Bioavailability of Quercetin from Flesh Scales and Dry Skin of Onion in Rats. Pol J Food Nutr Sci. 2003; 12: 95-99.

69. Wu LX, Guo CX, Chen WQ, et al. Inhibition of the organic anion-transporting polypeptide $1 \mathrm{~B} 1$ by quercetin: an in vitro and in vivo assessment. Br J Clin Pharmacol. 2012; 73(5): 750-757, doi: 10.1111/j.1365-2125.2011.04150.x, indexed in Pubmed: 22114872.

70. Yamazaki Y, Ueda T, Kohli Y, et al. Importance of acidic mucin secretions by foveolar and mucous neck cells of rat fundic mucosa as the defence mechanisms against $\mathrm{HCl}$ as revealed by fasting. Eur J Histochem. 1992; 36(2): 161-176, indexed in Pubmed: 1380850.

71. Yang JH, Hsia TC, Kuo HM, et al. Inhibition of lung cancer cell growth by quercetin glucuronides via G2/M arrest and induction of apoptosis. Drug Metab Dispos. 2006; 34(2): 296-304, doi: 10.1124/dmd.105.005280, indexed in Pubmed: 16280456.

72. Yao LH, Jiang YM, Shi J, et al. Flavonoids in food and their health benefits. Plant Foods Hum Nutr. 2004; 59(3): 113-122, indexed in Pubmed: 15678717.

73. Ye B, Zhou PY, Jia M, et al. Absence of NF- $\kappa$ B subunit $p 50$ ameliorates cold immobilization stress-induced gastric ulcers. Biochem Biophys Res Commun. 2013; 434(3): 547-551, doi: 10.1016/j.bbrc.2013.03.112, indexed in Pubmed: 23583384.

74. Zahorodny̆ MI. [Effect of quercetin on sodium diclofenacinduced ulceration]. Lik Sprava. 2003(1): 96-99, indexed in Pubmed: 12712624. 